\title{
Is Methylene Blue as Innocent as We Think in Breast Cancer Surgery?
}

\author{
Meme Kanseri Cerrahisinde Metilen Mavisi Düşündüğümüz Kadar Masum Mu? \\ iD Fazilet Erözgen ${ }^{1}$, (iD Alp Ömer Cantürk ${ }^{1}$, (iD) Türkan İkizceli ${ }^{\mathbf{2}}$ \\ 1 - Sağlık Bilimleri Üniversitesi, İstanbul Haseki Eğitim ve Araştırma Hastanesi, Genel Cerrahi Kliniği. \\ 2 - Sağlık Bilimleri Üniversitesi, İstanbul Haseki Eğitim ve Araştırma Hastanesi, Radyoloji Kliniği.
}

\begin{abstract}
Methylene blue is a widely used and safe method in the world to determine the axillary region in breast cancer surgery. When evaluating the axilla, it is recommended to examine the sentinel lymph node after methylene blue marking. Methylene blue is an inexpensive and effective method for detecting axillary regions in breast surgery. It contains less risk. In some cases, it can lead to serious consequences that will require repetitive surgical interventions. It can sometimes lead to severe necrosis and sometimes to erythema and infection. In this respect, methylene blue not only causes complications that do not cause mortality, but can sometimes lead to poor cosmetic results.

682 patients who underwent breast cancer surgery, Istanbul Haseki Training and Research Hospital between 2015-2020 were compiled. Sentinel lymph node sampling was required in 372 of these patients. In this article, two complications occured as a result of methylene blue used during axillary sentinel lymph node sampling are presented.

$\ddot{O} Z \boldsymbol{E T}$

Meme kanseri cerrahisinde aksiller durumu belirlemekte metilen mavisi dünyada yaygın olarak kullanılan güvenli bir yöntemdir. Aksilla değerlendirilirken metilen mavisi işaretlemesi sonrası sentinel lenf nodu incelenmesi önerilen bir yaklaşımdır. Metilen mavisinin meme cerrahisinde aksiller durumu tespit etmede hem ucuz hem de efektif bir yöntemdir. Az da olsa risk içermektedir. Hatta bazı durumlarda tekrarlayan cerrahi girişimler gerektirecek ciddi sonuçlara yol açabilmektedir. Bazen ciddi nekrozlara bazen ise yara yerinde eritem ve enfeksiyona yol açabilmektedir. Bu yönüyle metilen mavisinin sadece mortaliteye yol açmayan komplikasyonlara neden olmakta kalmayıp, bazen de kozmetik kötü sonuçlara yol açabilmektedir.

İstanbul Haseki Eğitim ve Araştırma Hastanesi'nde 2015-2020 yılları arasında meme kanseri cerrahisi operasyonu geçirmiş olan 682 hastamız derlendi. Bu operayonların 372 'sinde sentinel lenf nodu örneklemesi gerekmiştir. Bu yazıda aksiller sentinel lenf nodu örneklemesi esnasında kullanılan metilen mavisinin sonucunda gelişmiş 2 adet komplikasyonu sunuldu.
\end{abstract}

\section{GİRIS:}

Meme kanseri, memede oluştuğu yerde, tümör yatağından aksillaya yayılmadan önce ilk birkaç lenf noduna yayılır (1). Bu ilk lenf nodlarına sentinel lenf nodu (SLN) denir ki primer tümörün ilk direne olduğu nodlardır. Sentinel lenf nodu biyopsisi (SNLB) tekniği ile bu lenf nodları belirlenerek histopatolojik verifikasyon için eksizyon yapilır ve aksiller lenf nodu diseksiyonuna (ALND) alternatif bir metod olarak rutin olarak uygulanmaktadir. $\mathrm{Bu}$ şekilde erken evre meme kanserli hastada SNLB ile diğer lenf nodları hakkında bilgi vererek, metastaz izlenmediğinde gereksiz ANLD'den kaçınılmış olunur $(2,3)$. SNLB tekniğinde öncelikle subdermal metilen mavisi enjekte edilir. Genellikle bir komplikasyon izlenmezken, bazı durumlarda nadir de olsa ciltte mavi renk değişiminden cilt nekrozuna varan geniş bir yelpazede komplikasyonlar ortaya çıkabilmektedir. Hatta literatürde metilen mavisi uygulamasına karşı gelișen sekonder anaflaksi vakaları bildirilmiștir (4,5). American Society of Clinical Oncology (ASCO) guide-linelar1, aksiller haritalamada metilen mavisi ile sentinel lenf nodu örneklemesinin başarısı en yüksek teknik olduğunu belirtmektedir. $\mathrm{Bu}$ yazıda belirtmek istediğimiz konu metilen mavisinin nadiren komplikasyonları olsa da hala çok güvenilir bir yöntem olduğu, fakat komplikasyonlar geliştiğinde de bunların ciddi olabileceğidir

İstanbul Haseki Eğitim ve Araştırma Hastanesi'nde 2015-2020 yılları arasında meme kanser cerrahisi geçirmiş olan 682 hastamız bulunmaktadır. Bu operasyonların 382'sinde sentinel lenf nodu örneklemesi gerekmiştir. İki hastamızda ise metilen mavisi sonucunda lokal ve sistemik komplikasyonlar gelişmiştir. $\mathrm{Bu}$ yazıda bu kompliksayonlar ve bunların yönetim şeklini paylaşmayı amaçladik. 


\section{Erozgen et al.}

\section{OLGU 1}

44 yaşında kadın hasta, sol memede infiltrafif duktal karsinom tanisı mevcuttu. Aksiller sentinel lenf nodu biopsisi ve subkutan mastektomi sonrası expander uygulanması yapıldı. Operasyon esnasında aksiller örnekleme amaçlı subareolar subdermal bölgeye metilen mavisi enjekte edilmişti. Postoperatif üçüncü günde uygulanan metilen mavisi noktalarında multipl cilt debridmanları gerektiren cilt nekrozu gelişmiştir. Bu nekrotik cildin yönetiminde rekonstrüksiyon işlemleri ve gecikmiş cilt kapama yöntemi uygulanmıştır. Hastada operasyondan sonra üçüncü günde ortaya çıkan sol memede ağrı şişlik ve kızarıklık ilk semptom olarak tespit edilmiştir. Operatör değerlendirmesi sonucunda bir hafta içerisinde yara yerinde enfeksiyon bulguları gözlenmiştir. Ardından ilerleyen süreçte poliklinik takiplerinde sol meme saat 3 ve saat 9 hizasında, metilen mavisinin uygulandığ 1 bölgelerde areola çevresinde de eritemin eşlik ettiği yara yeri enfeksiyonu ve gecikmiş dönemde her iki bölgede ayrı ayrı de cilt nekrozları saptanmıştır (resim 1a, b). Bunun tespit edilmesinin ardından hasta ikincil cerrahi işleme alınmış ve nekrotik dokunun tamamını içine alacak şekilde periareolar bölgeyi ve nipple-areola kompleksini koruyarak memenin saat 3 ve saat 9 hizasından horizontal insizyonlar yapılmış ve tüm nekrotik doku temizlenerek etkin debridman sağlanmıştır. Bu debridman sonrasında da hastaya 2 hafta süren oral antibiyoterapi rejimi tedavi sürecinde eklenmiştir. 2 hafta sonra herhangi bir komplikasyon görülmeden operasyon bölgesi tamamen iyileşmiştir (resim 2a, b).

$\mathrm{Bu}$ cerrahi işlemden 7 ay sonra hasta sol memedeki expander uygulamasına yönelik implant yerleştirilmesini içeren tekrar bir cerrahi işlem geçirdi. Bu esnada da sol memeye inferior pedikül ve wise cilt grefti ile redüksiyon mastopeksi işlemi uygulandı. Sol memenin eksizyon patolojisi multifokal grade-1 insitu lobüler karsinom ile ilişkili invaziv lobüler karsinom olarak geldi. Tümör çap1 $4.2 \mathrm{~cm}$ 'dir. ER \%100, PR \%100, c-erb B2 negatif, Ki-67 \%25-30 olarak saptanmıştır. Sonuç olarak hastamız implant bazlı meme rekonstrüksiyonu yöntemi kullanılarak başarılı bir cerrahi operasyon geçirmiştir.
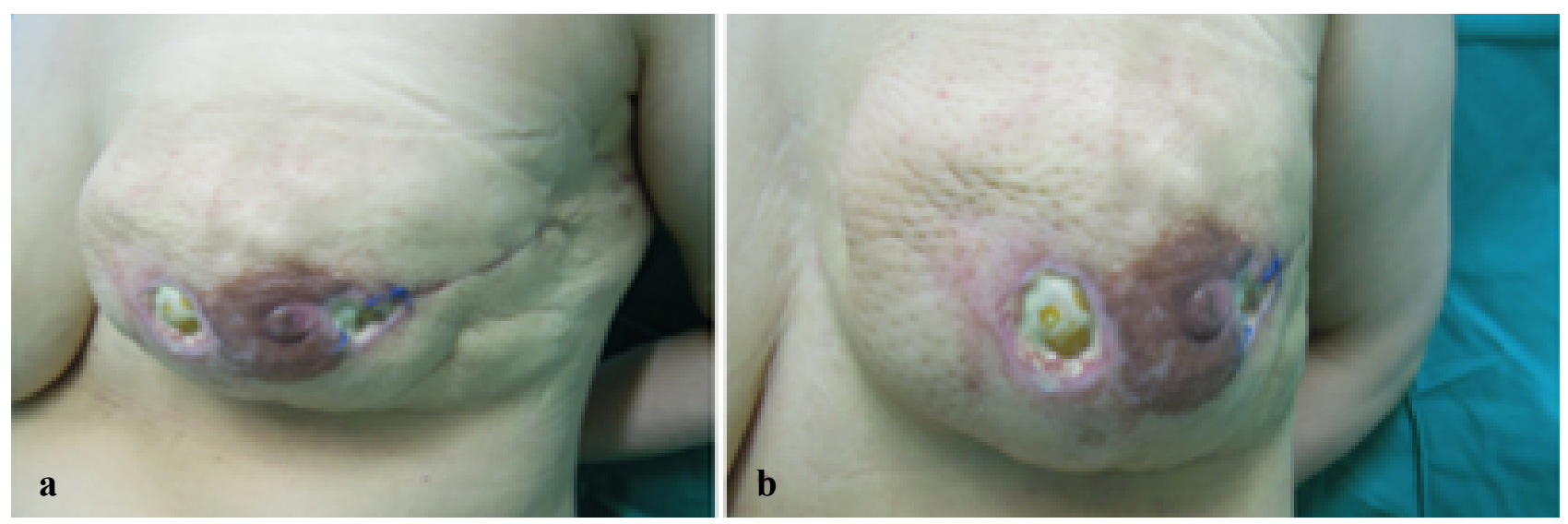

Resim 1: a, b) Postoperatif bir hafta içerisinde sol meme saat 3 ve saat 9 hizasında, metilen mavisinin uygulandığ1 bölgelerde ve areola çevresinde de eritemin eşlik ettiği enfeksiyon ve cilt nekrozları
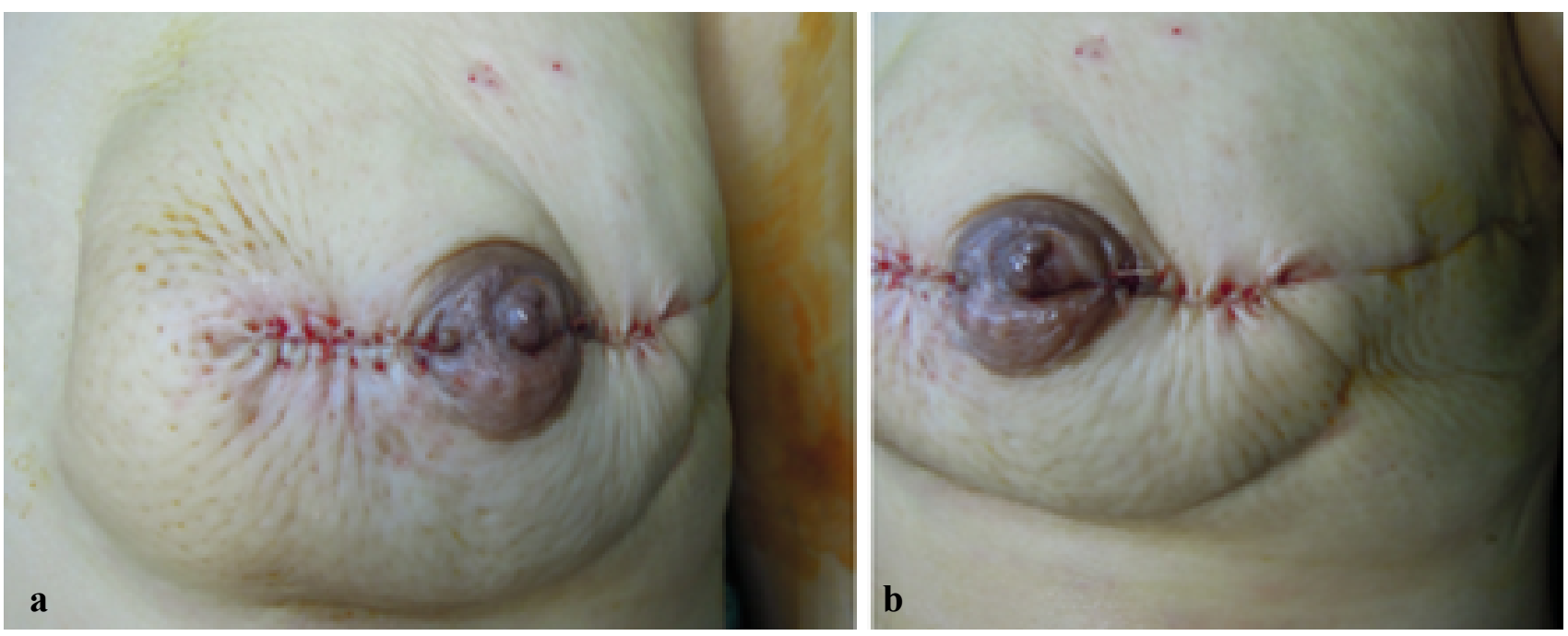

Resim 2: a, b) Periareoler bölgeyi ve nipple-areola kompleksini koruyarak memenin saat 3 ve saat 9 hizasından horizontal insizyonlar ile nekrotik doku debridmanı yapıldı. İki hafta süren oral antibiyotik tedavisi sonrası iyileşme sağlandı. 


\section{OLGU 2}

47 yaşında kadın hasta sol memede infiltratif duktal karsinom tanısı mevcuttu. Cerrahi işlem olarak sol segmenter mastektomi ve axiller sentinel lenf nodu örneklemesi yapıldı. Bu olguda da metilen mavisi subareoler subdermal bölgeye enjekte edildi. Cerrahi sonrası postoperatif ikinci günde hastanın operasyon bölgesinde kızarıklık ve 1sı artışı meydana geldi (resim 3a). Lokal enfeksiyon oral antibiyoterapi ve kortikosteroid kullanılarak konservatif olarak tedavi edildi. İki hafta sonra hastanın klinik tablosu normale döndü (resim 3b). Nihai patoloji sol memede T1 N0 M0 infiltratif duktal karsinom ile uyumlu olup tümör Ki-67 indeksi \%15 olarak saptand1.
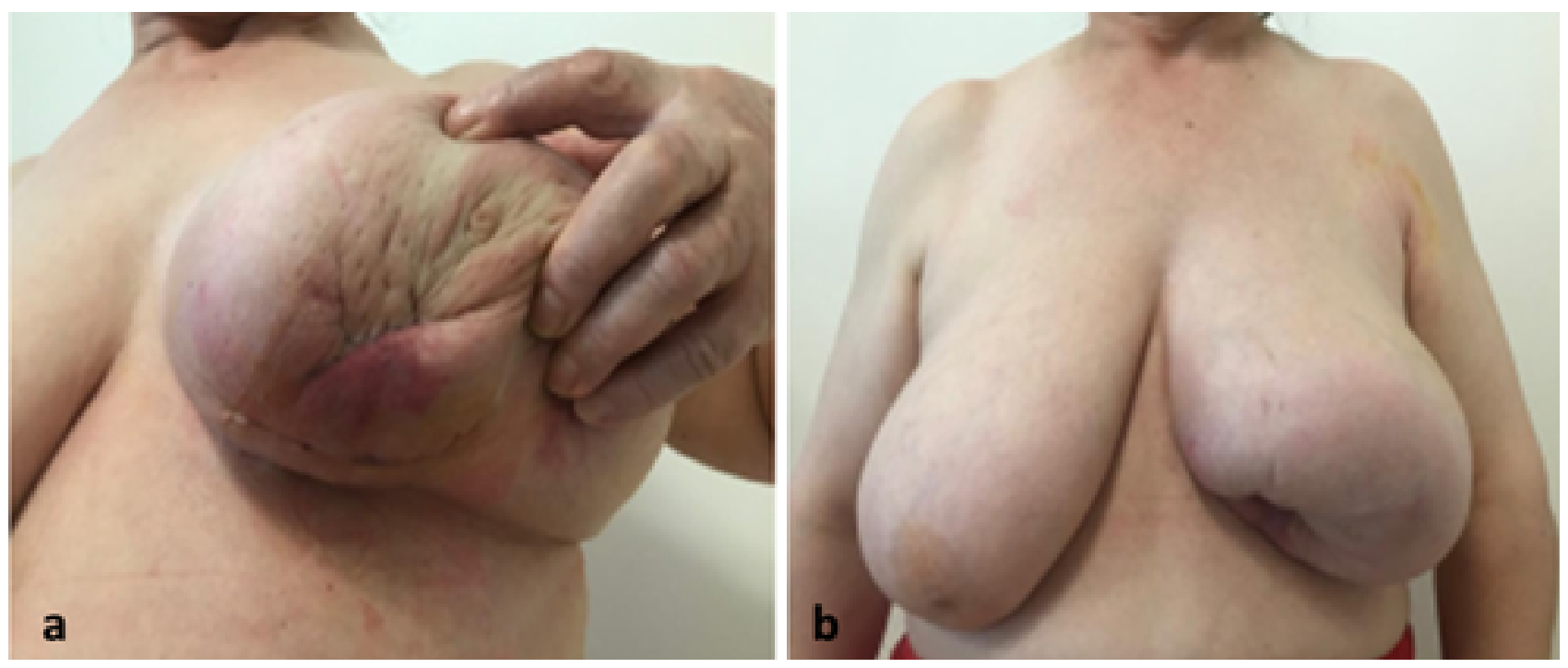

Resim 3: a) Postoperatif ikinci günde operasyon bölgesinde kızarıklık ve 1sı artışı b) antibiyoterapi ve kortikosteroid kullanılarak konservatif tedaviden iki hafta sonra iyileşme görüldü.

\section{TARTIŞMA}

Erken evre meme kanserlerinde sentinel lenf nodu tespiti oldukça önemlidir. SLN'nin tespiti için farklı uygulamalar mevcuttur. Yaygin kullanılan metod metilen mavisi olmakla birlikte s1klıkla radyoizotop ve metilen mavisi birlikte kullanımı en çok önerilen tekniktir. "Kombine Teknik" olarak adlandırılan bu teknikle \%99 başarı ile sentinel lenf nodu tespit edilebilmektedir $(7,8)$. Ancak kullanıcı deneyimine bağlı olarak kombine teknik yerine sadece radyoizotop kullanılarakta benzer sonuçların alındığı bildirilmektedir.

Literatürde çok sayıda yapılan çalışmalarda metilen mavisi kullanımına bağlı komplikasyonlar bildirilmiştir. Ürtiker, kaşıntı, ciltte mavilik, kızarıklık gibi Grade-I reaksiyon olarak adlandırılan reaksiyonlar \%69-87 oranında, geçici hipotansiyon gibi Grade-II raeaksiyonlar \%3,2-8 oaranında ve ciddi hipotansiyon (sistolik basincin $70 \mathrm{mmHg}$ altında olmas1) gibi Grade-III reaksiyonlar ise \%1,1 olarak bildirilmiştir. Tarif edilen bu alerjik reaksiyonların ciddiyetine göre tedaviler tanımlanmıştır. Grade-I ve Grade-II alerjik reaksiyonlar için kortikosteroid, antihistaminik ve kristaloid sıvilarlarla volüm replasmanı yapmak yeterli olabilir. Grade-III alerjik reaksiyonlar ise ciddidir ve yoğun bakım desteği gerektirebilecek vazopressör uygulaması gerekebilir (9). Bütün bunlardan çıkan bir sonuç olarak SNL'nu sapatamak için radyoizotop maddeyi tek başına kullanmak daha güvenilir gibi görülmektedir.

\section{Çıkar Çatışması:}

Yazarlar çıkar çatışması olmadığını bildirmiştir.
Klinik pratiğimizde kullandığımız metilen mavisine karş1 komplikasyon oranımız sadece $2(\% 0,4)$ olguda Grade-I reaksiyon şeklindeydi. Ancak olası alerjik reaksiyonlardan kaçınmak için sadece sıklıkla radyoizotop ile işlem yapılmaya devam edildi.

Metilen mavisi uygulaması farklı şekilde yapılabilmektedir. İntradermal veya intraparankimal enjeksiyonlar şeklinde de SNL yapılabileceği bildirilmiştir. Ancak intradermal metilen mavisi enjeksiyonundan sonra daha çok ciltte eritematöz lezyonlar, cilt nekrozu ve yüzeyel ülserlerin ortaya çıktığ 1 gösterilmiştir (10).

Metilen mavisi ciltte lokal enfeksiyondan cilt nekrozuna kadar geniş bir spektrumda etki edebilir. Bu yazıda 5 yıllık bir süreçte meme cerrahisi uyguladığımız hastaların verilerini paylaştık ve bu yıllar arasında metilen mavisi sonrası gelişmiş olan komplikayonları ve bunları yönetim şeklimizi rapor ettik. Metilen mavisi meme kanseri cerrahisinde aksilla sentinel lenf nodu örneklemesinde halen çok yaygın kullanılan güvenli bir yöntemdir. Fakat komplikasyon gelişmesi durumunda da bunun sonuçları tekrarlayan cerrahi girişimler gerektirecek kadar ciddi olabilmektedir. Metilen mavisine sekonder gelişmiş komplikayonlardan bazıları kozmetik açıdan kalıcı negatif etkilere yol açabilir. Komplikasyon gelişmesi durumunda ise bunların yönetimi bize gelişebilecek diğer komplikasyonları yönetme açısından yol gösterici olacaktır.
Teşekkür:

Yazarlar Dr. Ahmet Kocakuşak’a teşekkür eder. 


\section{Erozgen et al.}

\section{KAYNAKLAR:}

1. Tanis PJ, Nieweg OE, Olmos RAV, Rutgers EJ, Kroon BR. History of sentinel lymph node and validation of the technique. Breast Cancer Res. 2001;3:109-112.

2. Chen SL, Iddings DM, Scherri RP Bilchik AJ. Lymphatic mapping and sentinel node analysis: current concepts and applications. CA Cancer J Clin. 2006;56:293-309.

3. Kim T, Giuliano AE, Lyman GH. Lymphatic mapping and sentinel lymph node biopsy in early-stage breast carcinoma. A meta-analysis. Cancer. 2006;106:4-16

4. Parvaiz MA, Isgar B. Anaphylaxis, and blue urticaria associated with patent blue V injection. Anesthesia. 2012;67:1275-1276.

5. Brenet O, Lalourcey L, Queinnec M, Dupoiron D, Jayr C, Rosay H, et al. Hypersensitivity reactions to patent Blue V in breast cancer surgery: a prospective multicentre study. Acta Anesthesiol Scand. 2013;57:106-111.

6. Newman EA, Newman LA. Lymphatic mapping techniques and Sentinel lymph node biopsy in breast cancer. Surg Clin N Am. 2007;87:353-364.

7. Varghese P, Abdel-Rahman AT, Akberali S, Mostafa A, Gattuso JM, Carpenter R. Methylene blue dye-a safe and effective alternative for sentinel lymph node localization. Breast J. 2008;14(1):61-67.

8. Fisher B, Wolmark N, Bauer M, Redmond C, Gebhardt M. The accuracy of clinical nodal staging and of limited axillary dissection as a determinant of histologic nodal status in carcinoma of the breast. Surg Gynecol Obstet. 1981;152:765-772.

9. Albo D, Wayne JD, Hunt KK, Rahlfs TF, Singletary SE, Ames FC, et al. Anaphylactic reactions to isosulfan blue dye during sentinel lymph node biopsy for breast cancer. Am J Surg 2001;182:393-398.

10. Stradling BS, Aranha G, Gabram S. Adverse skin lesions after methylene blue injections for sentinel lymph node localization. Am J Surg. 2002;184:350-352. 